\title{
Calcitonin gene-related peptide: neuroendocrine communication between the pancreas, gut, and brain in regulation of blood glucose
}

\author{
Sayali A. Pendharkar, Monika Walia, Marie Drury, Maxim S. Petrov \\ School of Medicine, University of Auckland, Auckland, New Zealand \\ Contributions: (I) Conception and design: MS Petrov; (II) Administrative support: M Walia, M Drury; (III) Provision of study materials or patients: \\ SA Pendharkar, M Drury; (IV) Collection and assembly of data: SA Pendharkar, M Walia; (V) Data analysis and interpretation: SA Pendharkar, MS \\ Petrov; (VI) Manuscript writing: All authors; (VII) Final approval of manuscript: All authors. \\ Correspondence to: Dr. Maxim S. Petrov, MD, MPH, PhD. School of Medicine, University of Auckland, Rm 12.085A, Level 12, Auckland City \\ Hospital, Auckland 1142, New Zealand. Email: max.petrov@gmail.com.
}

\begin{abstract}
Background: Calcitonin gene-related peptide (CGRP), a ubiquitous neuropeptide, plays a diverse and intricate role in chronic low-grade inflammation, including conditions such as obesity, type 2 diabetes, and diabetes of the exocrine pancreas. Diabetes of exocrine pancreas is characterised by chronic hyperglycemia and is associated with persistent low-grade inflammation and altered secretion of certain pancreatic and gut hormones. While CGRP may regulate glucose homeostasis and the secretion of pancreatic and gut hormones, its role in chronic hyperglycemia after acute pancreatitis (CHAP) is not known. The aim of this study was to investigate the association between CGRP and CHAP.

Methods: Fasting blood samples were collected to measure insulin, HbA1c, CGRP, amylin, C-peptide, glucagon, pancreatic polypeptide (PP), somatostatin, gastric inhibitory peptide, glicentin, glucagon-like peptide-1 and 2, and oxyntomodulin. Modified Poisson regression analysis and linear regression analyses were conducted. Five statistical models were used to adjust for demographic, metabolic, and pancreatitisrelated risk factors.

Results: A total of 83 patients were recruited. CGRP was significantly associated with CHAP in all five models ( $\mathrm{P}$-trend $<0.005)$. Further, it was significantly associated with oxyntomodulin $(\mathrm{P}<0.005)$ and glucagon $(\mathrm{P}<0.030)$. Oxyntomodulin and glucagon independently contributed $9.7 \%$ and $7 \%$, respectively, to circulating CGRP variance. Other pancreatic and gut hormones were not significantly associated with CGRP.

Conclusions: CGRP is involved in regulation of blood glucose in individuals after acute pancreatitis. This may have translational implications in prevention and treatment of diabetes of the exocrine pancreas.
\end{abstract}

Keywords: Acute pancreatitis; calcitonin gene-related peptide (CGRP); diabetes of the exocrine pancreas; gut hormones; pancreatic hormones

Submitted Jul 30, 2017. Accepted for publication Aug 15, 2017.

doi: $10.21037 /$ atm.2017.08.27

View this article at: http://dx.doi.org/10.21037/atm.2017.08.27

\section{Introduction}

Diabetes of the exocrine pancreas has been recognised as an important clinical entity for decades $(1,2)$. While its statistics were, until recently, largely confined to chronic pancreatitis and pancreatic cancer $(3,4)$, emerging large scale population-based studies show that more than $60 \%$ of all cases of diabetes of the exocrine pancreas are due to new-onset diabetes after acute pancreatitis (NODAP) (5-7), and that the risk of NODAP may not depend on severity of acute pancreatitis $(8,9)$. However, the molecular mechanisms underlying the pathophysiology of NODAP remain unclear. Clinical studies have shown that the 
calcitonin family of peptides (more specifically, procalcitonin and amylin) is associated with chronic lowgrade inflammation in individuals with obesity, diabetes, and after acute pancreatitis (10-14). Human adipose tissue depots have been identified as a major site of pro-calcitonin mRNA with recent studies reporting calcitonin secretion from adipocytes in obese individuals with associated insulin resistance $(15,16)$. Increasing body of evidence shows that abdominal adiposity is also involved in metabolic dysregulations following an episode of acute pancreatitis (17-19). Further, elevated amylin levels have been reported in patients with chronic alcoholic pancreatitis and abnormal glucose metabolism (13), with similar findings reported in a study involving patients with acute pancreatitis that found a significant correlation between amylin and abnormal glucose metabolism $(20,21)$.

Calcitonin gene-related peptide (CGRP) is another member of the calcitonin family of peptides that consists of 37-amino acids $(14,22)$. There are two isoforms of CGRP (synthesized from two distinct genes): $\alpha C G R P$, found predominantly in the central and peripheral nervous systems, and $\beta C G R P$, found mainly in the enteric nervous system (23). In humans, the two isoforms are $>90 \%$ homologous and differ in only three amino acids (14). CGRP binds to a heteromeric receptor comprising of G-protein coupled receptor, called calcitonin receptor-like receptor (CLR), and a receptor activitymodifying protein (RAMP) $(14,24,25)$. Both $\alpha$ CGRP and $\beta C G R P$ bind to the CGRP receptor (CGRPr) - a CLR/ RAMP1 complex, and with lower affinity to the receptors of other peptides of the family to mediate numerous functions $(14,24)$. CGRP has been extensively investigated in the setting of infections and migraine, and acts as both a nociceptive and effector factor in the latter $(14,23)$. It is also a well-established potent vasodilator and has a vascular protective role in cardiovascular diseases such as ischemia and arterial hypertension (14). Both isoforms of CGRP were found to be present in the pancreas, with $\beta C G R P$ found to be co-localized with insulin and amylin in pancreatic $\beta$ cells and interact with insulin receptors (26-28). However, findings from pre-clinical and clinical studies on the effect of CGRP on insulin secretion are contradictory. Evidence from pre-clinical studies suggests that CGRP stimulates insulin secretion (29-31) in a dose-dependent manner while data from clinical studies show an inhibitory effect of CGRP on insulin secretion $(32,33)$. Recent studies suggest that certain pancreatic [insulin, amylin, pancreatic polypeptide (PP)] and gut hormones (glicentin, oxyntomodulin) are altered in patients with abnormal glucose metabolism after acute pancreatitis $(20,21,34)$. There is sufficient evidence, spanning nearly two decades, on the influence of CGRP on the secretion of pancreatic and gut hormones, in particular glucagon, somatostatin, and glucagon like peptide (GLP)-1 (26,27,35,36). Intravenous infusion of CGRP in rats results in a dose-dependent increases in basal secretions of glucagon, GLP-1 and GLP-2 $(37,38)$. In the rat pancreas, CGRP is co-localized with somatostatin and is known to stimulate its release, though effect of CGRP on insulin inhibition does not appear to be modulated by the somatostatin pathway $(28,39)$. While CGRP plays multifaceted roles in metabolism, its role in the pathogenesis of chronic hyperglycemia after acute pancreatitis (CHAP) remains to be investigated.

The primary aim of this study was to investigate the association between CGRP and CHAP, and the effect of covariates. The secondary aims were to investigate the associations between CGRP and panels of pancreatic and gut hormones known to play a role in glucose metabolism.

\section{Methods}

\section{Study design}

The study was a cross-sectional study of patients admitted to Auckland City Hospital (Auckland, New Zealand) with acute pancreatitis from 2010 to 2014. The study protocol was approved by the Health Disability Ethics Committee (13/STH/182).

\section{Study population}

Individuals who had a primary diagnosis of acute pancreatitis (based on two of the following three criteria: abdominal pain indicative of acute pancreatitis; and/or serum amylase ( $\geq 405 \mathrm{U} / \mathrm{L})$ and/or pancreatic amylase ( $\geq 159 \mathrm{U} / \mathrm{L}$ ) and/or lipase ( $\geq 201 \mathrm{U} / \mathrm{L}$ ) levels at least three times the upper limit of normal; and/or radiological findings of acute pancreatitis), resided in Auckland at the time of the study, and were at least 18 years of age were eligible for the study. All eligible individuals who provided informed consent were invited to the hospital to participate in the study. For those individuals unable to attend the hospital, a certified phlebotomist conducted home visits.

Individuals who had chronic pancreatitis, malignancy, post-endoscopic retrograde cholangiopancreatography 
pancreatitis, intraoperative diagnosis of pancreatitis, prediabetes or diabetes before the first hospital admission due to acute pancreatitis, cognitive disability, or were pregnant were excluded from the study.

\section{Definitions}

* Aetiology was categorised into biliary, alcoholinduced, or other;

- Body mass index (BMI) $\left(\mathrm{kg} / \mathrm{m}^{2}\right)$ was determined using a medical scale with stadiometer;

* Chronic hyperglycemia following acute pancreatitis was defined as glycated haemoglobin A1c (HbA1c) $\geq 39 \mathrm{mmol} / \mathrm{mol}(1)$;

* Duration was defined as time (months) from first attack of acute pancreatitis to the time of study;

- Normoglycemia was defined as HbAlc $\leq 38 \mathrm{mmol} / \mathrm{mol}$ (1);

* Recurrence: participants admitted with more than one episode of acute pancreatitis at the time of the study were determined as having recurrent acute pancreatitis;

* Severity of acute pancreatitis was determined according to the 2012 Determinant-Based Classification (40).

\section{Sample acquisition and storage}

All participants were required to fast for at least eight hours prior to visiting the clinic at $8.00 \mathrm{am}$. Participants were then accompanied to LabPlus, an International Accreditation New Zealand accredited medical laboratory at Auckland City Hospital, where venous blood was collected by a certified phlebotomist. Blood was centrifuged at $4{ }^{\circ} \mathrm{C}$ for $7.5 \mathrm{~min}$ at $4,000 \mathrm{~g}$. Plasma was separated, aliquoted, and stored at $-80^{\circ} \mathrm{C}$ until use.

\section{Laboratory assays}

Insulin and HbA1c were analysed at LabPlus using the chemiluminescence sandwich immunoassay (Roche Diagnostics NZ Ltd., Auckland, New Zealand), and the boronate affinity chromatography assay (Trinity Biotech, Co. Wicklow, Ireland), respectively.

The Merck-Millipore ELISA kits were used in accordance with the user's manual to measure CGRP, GIP, GLP-1 and $-2(\mathrm{ng} / \mathrm{mL})$, oxyntomodulin $(\mathrm{ng} / \mathrm{mL})$, somatostatin, and glicentin (pmol/L). Aprotinin inhibitor was added to all assays upon blood withdrawal except for
GLP-1, to which the DPP4 inhibitor was added. The Rayto Microplate Reader (V-2100C, Santa Fe, Granada, Spain), with an absorbance range of 405-630 nm was used. The intra- and inter-assay variation was $<10 \%$ and $15 \%$, respectively.

The MILLIPLEX MAP Human Metabolic Hormone magnetic bead panel based on the Luminex xMAP technology was used to measure amylin, C-peptide, glucagon, and PP $(\mathrm{ng} / \mathrm{mL})$. The protease inhibitor cocktail was added to amylin and the aprotinin inhibitor to glucagon. The intra- and inter-assay variation for amylin was $<10 \%$ and $20 \%$, respectively while for C-peptide, glucagon, and PP, it was $<10 \%$ and $15 \%$, respectively.

\section{Statistical analyses}

All analyses were conducted using SPSS for Windows Version 24 (IBM Corp., Armonk, New York, USA) and P values $<0.05$ were accepted as statistically significant.

The chi-square test and student's $t$-test were used to investigate the differences in categorical and continuous baseline characteristics, respectively, between patients with normoglycaemia and CHAP. Data were either presented as frequency or mean \pm standard deviation (SD). The subsequent statistical analyses were conducted in three steps.

First, a modified Poisson regression analysis was conducted to investigate the association between CGRP and CHAP. CGRP was categorised into quartiles based on predetermined concentration ranges (calculated using the frequency function). To calculate the P-trend, each participant was assigned the median value in their quartile which was assessed as a continuous variable. CGRP was investigated as an independent variable in one unadjusted and four adjusted models (41). Model 1 was the unadjusted model. Model 2 was adjusted for age, sex, ethnicity, and BMI. Model 3 was adjusted for pancreatitis-related risk factors (recurrence, severity of acute pancreatitis, duration, and aetiology). Model 4 was adjusted for all potential confounders: age, sex, ethnicity, BMI, recurrence, severity of acute pancreatitis, duration, aetiology, smoking, and physical activity. Model 5 was adjusted for those risk factors found to be statistically significant in model 4. Pearson's chi-square and robust estimator were fit as the scale parameter and covariance matrix, respectively to account for any over-dispersion and to obtain the most robust estimates. The offset value was set at 1 . A main-effects model was fit 
Table 1 Baseline characteristics of study participants

\begin{tabular}{|c|c|c|c|}
\hline Characteristic & $\begin{array}{l}\text { Normoglycemia } \\
\qquad(n=64)\end{array}$ & $\begin{array}{c}\text { Chronic } \\
\text { hyperglycemia } \\
(n=19)\end{array}$ & $\mathrm{P}$ \\
\hline Age (years) ${ }^{*}$ & $48 \pm 15$ & $61 \pm 12$ & $0.001^{\#}$ \\
\hline Sex & & & $0.020^{\#}$ \\
\hline Male & 35 & 16 & \\
\hline Female & 29 & 3 & \\
\hline Ethnicity & & & $0.024^{\#}$ \\
\hline Europeans & 35 & 12 & \\
\hline Maori & 3 & 3 & \\
\hline Pacific Islanders & 3 & 0 & \\
\hline Asian & 5 & 4 & \\
\hline Other & 18 & 0 & \\
\hline BMI $\left(\mathrm{kg} / \mathrm{m}^{2}\right)^{\star}$ & $27.42 \pm 5.20$ & $30.05 \pm 6.51$ & 0.072 \\
\hline Aetiology & & & 0.775 \\
\hline Biliary & 28 & 9 & \\
\hline Alcohol & 15 & 3 & \\
\hline Other & 21 & 7 & \\
\hline Recurrence & & & 0.393 \\
\hline No & 45 & 14 & \\
\hline Yes & 19 & 5 & \\
\hline Severity & & & $0.008^{\#}$ \\
\hline Mild & 57 & 11 & \\
\hline Moderate & 5 & 6 & \\
\hline Severe/Critical & 2 & 2 & \\
\hline $\begin{array}{l}\text { Duration from } 1^{\text {st }} \\
\text { attack of AP (months) }\end{array}$ & $28 \pm 29$ & $32 \pm 18$ & 0.613 \\
\hline Smoking & & & 0.577 \\
\hline Yes & 51 & 14 & \\
\hline No & 13 & 5 & \\
\hline Physical activity & & & 0.668 \\
\hline Yes & 17 & 6 & \\
\hline No & 47 & 13 & \\
\hline
\end{tabular}

*, data are presented as mean \pm standard deviation (SD); ",

$P$ values $<0.05$. AP, acute pancreatitis; BMI, body mass index. for all five models in order to derive the most conservative estimates. Data were presented as prevalence ratios (PR) with corresponding $95 \%$ confidence intervals (CI) and $P$ values.

Second, a linear regression analysis was conducted to investigate the association between CGRP and pancreatic hormones (amylin, glucagon, insulin, PP, and somatostatin) and derivative (C-peptide), and gut hormones (GIP, glicentin, glucagon, GLP-1, GLP-2, and oxyntomodulin). Each pancreatic hormone and gut hormone was investigated as a dependent variable in the above mentioned one unadjusted and four adjusted models. All data were presented as $\beta$ coefficients with corresponding $95 \% \mathrm{CI}$ and $P$ values.

Last, a linear regression analysis was conducted to investigate the contribution of each of the pancreatic and gut hormone to the variance of CGRP. Each pancreatic hormone and gut hormone was investigated independently and in combination with every other pancreatic and gut hormone. The most robust $\mathrm{R}^{2}$ value for each model was reported.

\section{Results}

\section{Study population}

Table 1 shows the baseline characteristics of all study participants. Eighty-three individuals were recruited into the study. Of these, 51 (61\%) were men. The mean age of the entire study cohort was $51 \pm 15$ years. Nineteen participants $(23 \%)$ developed CHAP while 64 did not.

\section{Association between CGRP and chronic byperglycemia}

CGRP was significantly associated with CHAP in all five models (Figure 1). Compared with the lowest quartile, a PR (95\% CI, P-trend) of 0.75 (0.65-0.87; P-trend $<0.001)$ in the highest quartile differed most significantly in model 1 , followed by a PR of $0.79(0.68-0.92$; P-trend $=0.002)$ in model 2, a PR of $0.78(0.67-0.91$; P-trend $=0.002)$ and 0.78 $(0.67-0.92$; P-trend $=0.002)$ in models 3 and 4 , respectively, and a PR of 0.78 (0.67-0.92; P-trend $=0.003)$ in model 5 .

\section{Associations between calcitonin-gene related peptide and pancreatic hormones}

CGRP decreased with a change in concentration of 


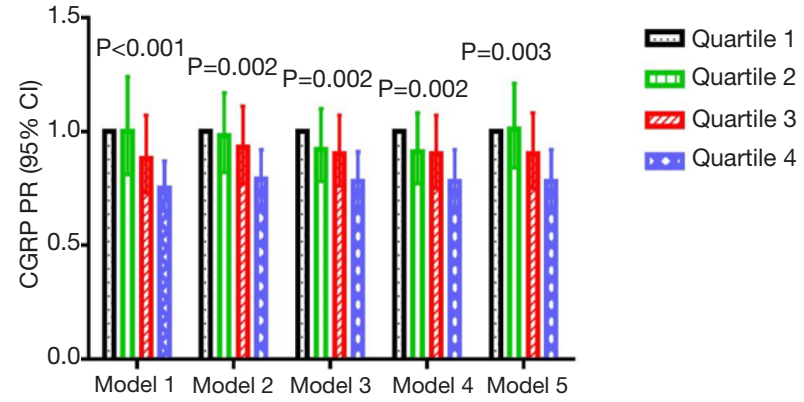

Figure 1 Association between calcitonin gene-related peptide and chronic hyperglycemia after acute pancreatitis. CGRP, calcitonin gene-related peptide; CI, confidence intervals; PR, prevalence ratio.

Table 2 Associations between calcitonin gene-related peptide and pancreatic hormones

\begin{tabular}{|c|c|c|}
\hline \multirow{2}{*}{ Pancreatic hormones } & \multicolumn{2}{|c|}{ Calcitonin gene-related peptide } \\
\hline & $\beta(95 \% \mathrm{Cl})$ & $P$ \\
\hline \multicolumn{3}{|l|}{ Amylin } \\
\hline Model 1 & $-9.44(-25.46$ to 6.59$)$ & 0.248 \\
\hline Model 2 & $-8.31(-24.61$ to 8.00$)$ & 0.340 \\
\hline Model 3 & $-11.43(-27.01$ to 4.15$)$ & 0.150 \\
\hline Model 4 & $-9.58(-25.51$ to 6.36$)$ & 0.239 \\
\hline Model 5 & $-9.44(-25.46$ to 6.59$)$ & 0.248 \\
\hline \multicolumn{3}{|l|}{ C-peptide } \\
\hline Model 1 & $-455.10(-1,002.74$ to 92.53$)$ & 0.103 \\
\hline Model 2 & $-456.02(-1,010.86$ to 98.82$)$ & 0.107 \\
\hline Model 3 & $-517.49(-1,060.93$ to 25.95$)$ & 0.062 \\
\hline Model 4 & $-507.14(-1,054.65$ to 40.36$)$ & 0.069 \\
\hline Model 5 & $-395.28(-9,40.02$ to 149.46$)$ & 0.155 \\
\hline \multicolumn{3}{|l|}{ Glucagon } \\
\hline Model 1 & $-32.33(-61.08$ to -3.59$)$ & $0.027^{\#}$ \\
\hline Model 2 & $-30.53(-62.83$ to -4.51$)$ & $0.024^{\#}$ \\
\hline Model 3 & $-37.15(-65.31$ to -8.98$)$ & $0.010^{\#}$ \\
\hline Model 4 & $-29.52(-65.81$ to -7.41$)$ & $0.014^{\#}$ \\
\hline Model 5 & $-32.33(-61.08$ to -3.59$)$ & $0.027^{\#}$ \\
\hline \multicolumn{3}{|l|}{ Insulin } \\
\hline Model 1 & $-17.89(-46.67$ to 7.90$)$ & 0.174 \\
\hline Model 2 & $-7.38(-30.52$ to 15.75$)$ & 0.532 \\
\hline Model 3 & $-17.06(-41.60$ to 7.48$)$ & 0.173 \\
\hline Model 4 & $-7.27(-28.18$ to 13.64$)$ & 0.496 \\
\hline Model 5 & $-6.99(-29.22$ to 15.24$)$ & 0.537 \\
\hline
\end{tabular}

Table 2 (continued)
Table 2 (continued)

\begin{tabular}{lcc}
\hline \multirow{2}{*}{ Pancreatic hormones } & \multicolumn{2}{c}{ Calcitonin gene-related peptide } \\
\cline { 2 - 3 } & \multicolumn{1}{c}{$\beta(95 \%$ Cl $)$} & $\mathrm{P}$ \\
\hline Pancreatic polypeptide & & \\
Model 1 & $-44.32(-104.81$ to 16.16$)$ & 0.151 \\
Model 2 & $-34.79(-92.26$ to 22.68$)$ & 0.235 \\
Model 3 & $-51.93(-109.10$ to 5.23$)$ & 0.075 \\
Model 4 & $-42.08(-98.94$ to 14.77$)$ & 0.147 \\
Model 5 & $-44.32(-104.81$ to 16.16$)$ & 0.151 \\
Somatostatin & $0.113(-0.246$ to 0.471$)$ & 0.538 \\
Model 1 & $0.066(-0.311$ to 0.443$)$ & 0.730 \\
Model 2 & $0.167(-0.182$ to 0.516$)$ & 0.348 \\
Model 3 & $0.138(-0.240$ to 0.516$)$ & 0.474 \\
Model 4 & $0.113(-0.246$ to 0.471$)$ & 0.538 \\
\hline
\end{tabular}

Data are presented as $\beta$ coefficients $(95 \% \mathrm{Cl})$. " , $\mathrm{P}$ values $<0.05$. Model 1 was the unadjusted model; model 2 was adjusted for age, sex, ethnicity, and BMl; model 3 was adjusted for aetiology, duration, severity of $\mathrm{AP}$, and recurrence; model 4 was adjusted for age, sex, ethnicity, BMI, aetiology, severity, duration, and recurrence; model 5 was adjusted for those confounders found to be significant in model 4 . No confounders were found to be statistically significant in model 4 of amylin, glucagon, pancreatic polypeptide, and somatostatin. Model 5 of insulin was adjusted for BMI and severity. BMI, body mass index.

glucagon in all five models (Table 2). For every $\mathrm{ng} / \mathrm{mL}$ change in glucagon, CGRP decreased by $37.15 \mathrm{ng} / \mathrm{mL}$ in model $3(\mathrm{P}=0.010)$, by $32.33 \mathrm{ng} / \mathrm{mL}$ in models $1(\mathrm{P}=0.027)$ and $5(\mathrm{P}=0.027)$, by $30.53 \mathrm{ng} / \mathrm{mL}$ in model $2(\mathrm{P}=0.024)$, and by $29.52 \mathrm{ng} / \mathrm{mL}$ in model $4(\mathrm{P}=0.014)$ (Table 2).

No change in CGRP concentration was observed with a change in concentrations of amylin, C-peptide, insulin, PP, and somatostatin in any of the five models (Table 2).

\section{Associations between CGRP and gut hormones}

CGRP increased with a change in concentration of oxyntomodulin in all five models (Table 3). For every $\mathrm{ng} / \mathrm{mL}$ change in oxyntomodulin, CGRP increased by $10.77 \mathrm{ng} / \mathrm{mL}$ in model $3(\mathrm{P}=0.002)$, by $10.86 \mathrm{ng} / \mathrm{mL}$ in model $2(\mathrm{P}=0.003)$, by $10.70 \mathrm{ng} / \mathrm{mL}$ in models $1(\mathrm{P}=0.003)$ and $5(\mathrm{P}=0.003)$, and by 10.45 in model $4(\mathrm{P}=0.004)$ (Table 3).

No change in CGRP concentration was observed with 
Table 3 Associations between calcitonin gene-related peptide and gut hormones

\begin{tabular}{|c|c|c|}
\hline \multirow{2}{*}{ Gut hormones } & \multicolumn{2}{|c|}{ Calcitonin gene-related peptide } \\
\hline & $\beta(95 \% \mathrm{Cl})$ & $P$ \\
\hline \multicolumn{3}{|c|}{ Gastric inhibitory peptide } \\
\hline Model 1 & $-20.77(-67.51$ to 25.98$)$ & 0.384 \\
\hline Model 2 & $-17.36(-62.37$ to 27.65$)$ & 0.450 \\
\hline Model 3 & $-19.54(-63.64$ to 24.57$)$ & 0.385 \\
\hline Model 4 & $-14.61(-58.19$ to 28.96$)$ & 0.511 \\
\hline Model 5 & $-17.23(-62.48$ to 28.02$)$ & 0.455 \\
\hline \multicolumn{3}{|l|}{ Glicentin } \\
\hline Model 1 & $1.50(-8.53$ to 0.09$)$ & 0.770 \\
\hline Model 2 & $2.22(-7.86$ to 12.29$)$ & 0.666 \\
\hline Model 3 & $0.34(-9.37$ to 10.06$)$ & 0.945 \\
\hline Model 4 & $1.24(-8.44$ to 10.93$)$ & 0.801 \\
\hline Model 5 & $1.50(-8.53$ to 0.09$)$ & 0.770 \\
\hline \multicolumn{3}{|c|}{ Glucagon-like peptide-1 } \\
\hline Model 1 & $30.34(-29.35$ to 90.03$)$ & 0.319 \\
\hline Model 2 & $24.63(-35.26$ to 84.52$)$ & 0.420 \\
\hline Model 3 & $27.09(-30.50$ to 84.67$)$ & 0.357 \\
\hline Model 4 & $26.73(-29.92$ to 83.38$)$ & 0.355 \\
\hline Model 5 & $36.70(-21.79$ to 95.20$)$ & 0.219 \\
\hline \multicolumn{3}{|c|}{ Glucagon-like peptide-2 } \\
\hline Model 1 & $1.10(-1.80$ to 3.99$)$ & 0.458 \\
\hline Model 2 & $1.03(-1.87$ to 3.92$)$ & 0.488 \\
\hline Model 3 & $1.38(-1.48$ to 4.23$)$ & 0.344 \\
\hline Model 4 & $1.16(-1.67$ to 3.99$)$ & 0.422 \\
\hline Model 5 & $1.10(-1.80$ to 3.99$)$ & 0.458 \\
\hline \multicolumn{3}{|l|}{ Oxyntomodulin } \\
\hline Model 1 & $10.70(3.67$ to 17.73$)$ & $0.003^{\#}$ \\
\hline Model 2 & $10.86(3.74$ to 17.97$)$ & $0.003^{\#}$ \\
\hline Model 3 & 10.77 (3.79 to 17.74$)$ & $0.002^{\#}$ \\
\hline Model 4 & 10.45 (3.40 to 17.51$)$ & $0.004^{\#}$ \\
\hline Model 5 & 10.70 (3.67 to 17.73$)$ & $0.003^{\#}$ \\
\hline
\end{tabular}

Data are presented as $\beta$ coefficients $(95 \% \mathrm{Cl})$. " , P values $<0.05$. Model 1 was the unadjusted model; model 2 was adjusted for age, sex, ethnicity, and BMl; model 3 was adjusted for duration, aetiology, severity of AP, and recurrence; model 4 was adjusted for age, sex, ethnicity, BMI, aetiology, severity, duration, and recurrence; model 5 was adjusted for those confounders found to be significant in model 4 . Model 5 of glucagon-like peptide- 1 was adjusted for smoking. None of the confounders were adjusted for in model 5 of glicentin, glucagon-like peptide-2, and oxyntomodulin. Model 5 of GIP was adjusted for recurrence. $\mathrm{BMI}$, body mass index. a change in concentrations of GIP, glicentin, GLP-1, and GLP-2 in any of the five models (Table 3).

\section{Contribution of pancreatic hormones and gut hormones to the variance of CGRP}

Figure 2 shows the contribution of each pancreatic hormone and gut hormone, both independently and in combination with each other, to the variance of CGRP. Of all the studied pancreatic and gut hormones, the three hormones independently contributing most to variance of circulating CGRP were oxyntomodulin (9.7\%), glucagon $(7.0 \%)$, and C-peptide (3.9\%). All the studied pancreatic hormones cumulatively contributed $13.5 \%$ to the circulating CGRP variance while all the studied gut hormones cumulatively contributed $9.7 \%$ to the circulating CGRP variance (Figure 2).

\section{Discussion}

This is the first clinical study to investigate the role of CGRP in dysregulation of glucose homeostasis following acute pancreatitis, as well as to study the associations between CGRP and comprehensive panels of pancreatic and gut hormones. The findings of this study show that circulating CGRP levels are significantly decreased in individuals with CHAP, consistently across all five statistical models. Further, CGRP was significantly associated with glucagon and oxyntomodulin, in all the studied models. Also, glucagon and oxyntomodulin were the largest independent contributors to circulating variance of CGRP. These findings may have important translational implications allowing timely identification of individuals with NODAP and possible prevention of this condition.

The significant association between CGRP and CHAP is a novel finding. The role of CGRP in glucose homeostasis is diverse and complex, given its presence in the central, peripheral, and enteric nervous system, as well as the pancreas $(23,27)$. Studies conducted predominantly in obese and type 2 diabetic rats have shown that infusion of pharmacological doses of CGRP induces insulin resistance and decreases peripheral glucose clearance $(15,24,42-47)$. Whether this holds true in patients with CHAP is not known. Nonetheless, there are several possibilities as to how CGRP may be involved in glucose homeostasis in patients after acute pancreatitis. The first possibility is that CGRP, known to be densely present in the pituitary tissue (48), interacts with $\alpha$ melanocyte 


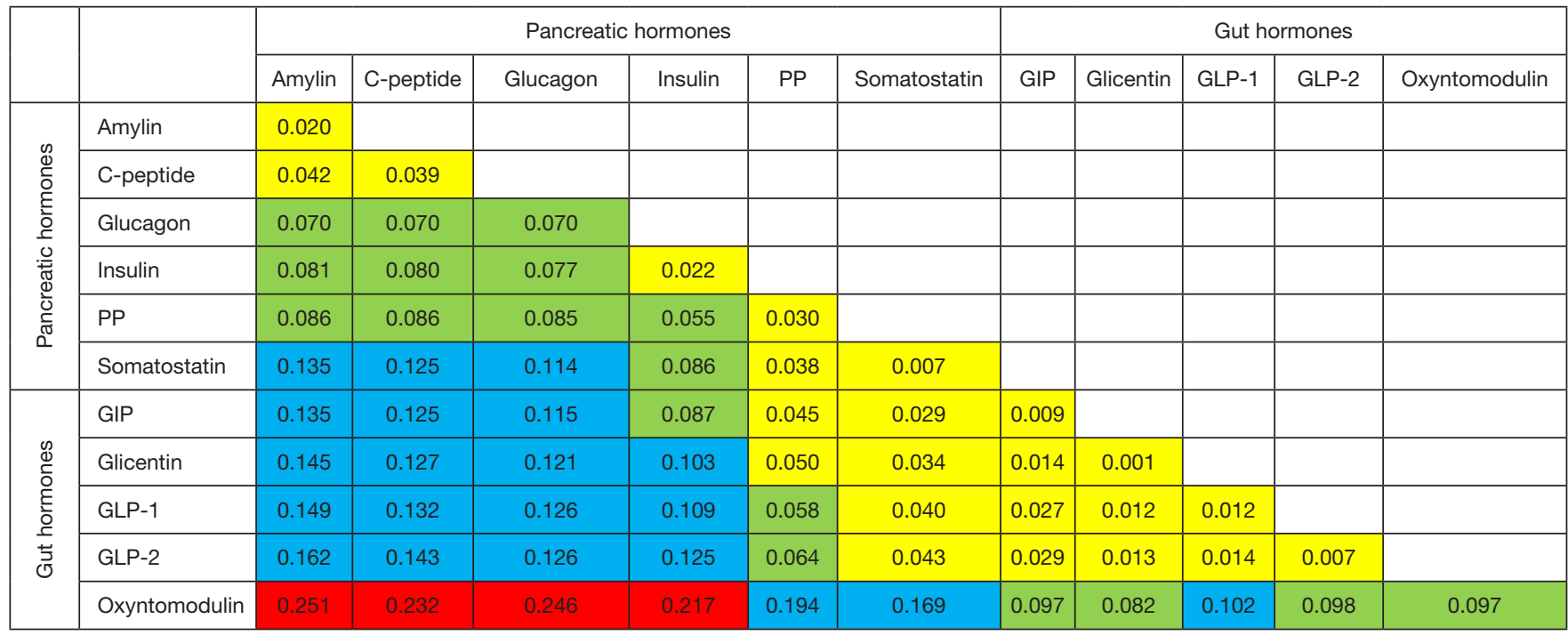

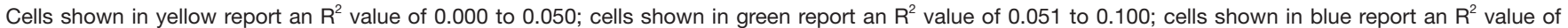

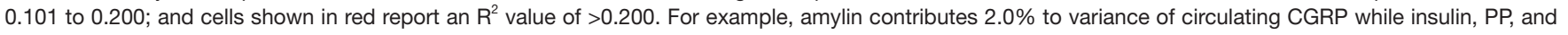

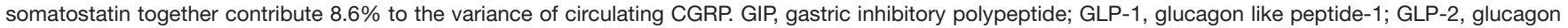
like peptide-2; PP, pancreatic polypeptide.

Figure 2 Contribution of pancreatic and gut hormones to the variance of calcitonin gene-related peptide

stimulating hormone (MSH) (48-50) to stimulate the release of glucoregulatory peptides such as oxyntomodulin from the enteroendocrine L cells. The melanocortin-4 receptor (MC4R), expressed in up to 150 regions in the brain, is one of the most enriched G-protein coupled receptor in oxyntomodulin-expressing $\mathrm{L}$ cells. Mutations causing loss of MC4R function are known to result in hyperinsulinemia among other things (48). A pre-clinical study by Panaro et al. (51) showed that intraperitoneal administration of $\alpha \mathrm{MSH}$ induces a MC4R-dependent release of peptide $\mathrm{YY}$, another neurotransmitter that is co-localized with CGRP, as well as proglucagon-derived GLP-1 (from L cells). This is further supported by the findings of this study that CGRP was significantly associated with CHAP and with oxyntomodulin — another proglucagon derivative. While there is a large body of evidence on interaction between calcitonin and pro-glucagon $(12,52-54)$, the association between CGRP and oxyntomodulin, with oxyntomodulin alone contributing 9.7\% to circulating CGRP variance, has been reported for the first time in this study. Lack of clinical studies investigating these peptides and their associations prevented progress in understanding the underlying mechanisms of what drives changes in these peptides. However, in the light of emerging evidence, it is not unreasonable to suggest that the cross-talk between the gut and the nervous system, termed the gut-brain axis, could be a key player in mediating glucose homeostasis in individuals with CHAP. While food ingestion is thought to be the primary trigger of gutbrain axis under physiological conditions, this study found detectable fasting blood levels of each studied pancreatic and gut hormone in more than $90 \%$ of individuals. Given that the effect of food can be ruled out, findings reported in this study suggest that there must be other stimulators, such as neurotransmitters and $\alpha \mathrm{MSH}$ involved in production and secretion of these glucoregulatory peptides. Given these findings, and taking into account that both CGRP and oxyntomodulin are produced in the gut and the brain, we believe it is now important to focus research efforts on the communication between the gut and the brain in patients with CHAP.

The second possibility as to how CGRP may be involved in glucose homeostasis in patients after acute pancreatitis is that CGRP plays a role in gut barrier dysfunction. Gut microbiota along with disrupted gut barrier function is an important component in metabolic disorders in particular obesity, hepatic steatosis, and diabetes-all characterised by persistent low-grade inflammation (55). Pre-clinical studies showed that procalcitonin precursors circulate freely in the blood under normal physiological conditions with elevated circulating levels at time of severe infection or systemic inflammation. The main stimuli for production and 
secretion of calcitonin precursors, from nearly every tissue in the body, are endotoxin and cytokines, which are also involved in maintaining gut barrier function (56). Given that calcitonin and CGRP are derived from the same gene, encoded on chromosome 11, and have similar biological functions (56), we speculate that endotoxin and cytokines also stimulate secretion of CGRP. Ammori et al. (56), based on a study involving 60 acute pancreatitis patients, hypothesised that early derangement of gut barrier function and the rise in systemic endotoxin exposure may act as a stimulus for secretion of calcitonin precursors. Although the role of endotoxin in CHAP has never been investigated, numerous studies have reported elevated cytokine levels in patients with abnormal glucose metabolism after acute pancreatitis $(57,58)$. Further, it is also known that gut barrier dysfunction occurs in almost $60 \%$ of acute pancreatitis patients (irrespective of the severity of disease) and results in amplified effect of intestinal microbiota on gut-brain communications (59). Given that CGRP is present in the central, peripheral, and enteric nervous system, and is a procalcitonin derivative, we suggest that CGRP may modulate glucose homeostasis via the gut barrier function pathway. To substantiate this hypothesis, future studies investigating associations between tight-junction proteins of the gut, such as occluding and zonula occludens 1 , and CGRP are required.

Enteroendocrine peptides present an attractive track among mechanisms involved in regulating gut permeability and gut microbiota (60). Pre-clinical studies by Cani et al. (55), Pachikian et al. (61), and Neyrinck et al. (62) showed that, upon administering a GLP-2 antagonist in obese and type 2 diabetic mice, gut barrier function improved and endotoxinaemia reduced. The authors thus suggested that proglucagon derived peptides, particularly GLP-2, are responsible for regulating intestinal epithelial proliferation and gut barrier integrity. Given that oxyntomodulin is a proglucagon derivative and co-localized with GLP-1 and GLP-2 in the L cells, it is possible that decreased oxyntomodulin and CGRP levels, as well as elevated levels of pro-inflammatory cytokines (57), may act as early indicators of a gut barrier dysfunction-associated chronic hyperglycemia. Although no clinical study to date has investigated the association between gut barrier function and diabetes of the exocrine pancreas, significant association between insulin resistance, $\mathrm{HbA1c}$, fasting blood glucose and gut microbiota has been reported in clinical studies involving type 2 diabetes patients $(60,63,64)$. Prebiotics, shown to improve glucose homeostasis, gut permeability, endotoxinaemia, inflammation, body weight, fat mass accumulation, and lipid metabolism-all associated with and implicated in the pathogenesis of acute pancreatitis, also induce changes in circulating levels of GLP-1, GIP, ghrelin, and peptide YY $(65,66)$. Studies investigating specifically the role of gut microbiota in patients with CHAP, and prebiotics as a potential therapeutic option, are now warranted.

The third possibility is that amylin, an evolutionary homologue of CGRP, competes with CGRP to bind to CGRPr and mediate glucose homeostasis, and that the decrease in circulating CGRP levels could be attributed to its inutility and short half-life (<10 min) (24). Amylin, first isolated from amyloid deposits of insulinoma and type 2 diabetes pancreas (67) in late 1980s, shares $43 \%$ and $46 \%$ homology with $\alpha$-CGRP and $\beta$-CGRP, respectively (68). Evidence from numerous pre-clinical studies shows that $(28,69-73)$, whereas amylin acts to reduce glucose-stimulated insulin release in non-insulin dependent diabetic rat islets, increased amylin causes peripheral insulin resistance possibly by acting directly on insulin secretion within the islet. Although the authors of aforementioned studies suggest that CGRP likely impairs insulin secretion and induces insulin resistance in the same manner as amylin $(28,69-73)$ in non-insulin dependent diabetes, our findings suggest that CGRP may be involved in glucose homeostasis only in the absence or non-functionality of amylin. This is supported by recent evidence that shows amylin levels are elevated in patients with abnormal glucose metabolism after acute pancreatitis $(20,21)$, and are significantly associated with pro-inflammatory cytokines, in particular interleukin-6 and monocyte chemoattractant protein-1 (21). Taken together, these suggest that amylin contributes significantly to glucose dysregulation in patients after acute pancreatitis.

The other possibility is that in patients with CHAP, the CGRP-glucagon pathway is compromised. A clinical study by Kraenzlin et al. (36), involving six healthy individuals in the fasted state, investigated the effect of CGRP on gastrointestinal hormones. The study showed that, upon intravenous infusion of CGRP $(0.32-2.56 \mathrm{pmol} / \mathrm{kg} / \mathrm{min})$ at every 15 for $45 \mathrm{~min}$, there was a significant decrease in GIP and enteroglucagon levels. Further, this inhibition was sustained for at least $60 \mathrm{~min}$ after stopping CGRP infusion while no significant change was observed in plasma insulin levels (36). Findings of our study differ from those reported in the study by Kraenzlin et al. in that glucagon was not significantly associated with an increase in CGRP levels, but a decrease; not to mention it alone contributed to $7 \%$ 
(which was more than half (52\%) of the contribution of all studied gut hormones cumulatively) of circulating CGRP variance. Another study by Beglinger et al. (26), involving nine healthy male volunteers in the fasted state, investigated the effect of synthetic CGRP on pancreatic secretions. The study reported no significant change in basal pancreatic hormone concentrations upon intravenous administration of CGRP, though fasting blood glucose levels increased with higher dose of CGRP. Under physiological conditions, glucagon is released from pancreatic $\alpha$-cells to stimulate glucose secretion and inhibit insulin secretion. However, patients with acute pancreatitis demonstrate elevated glucose and insulin levels (20). This difference in findings reported in the previous clinical studies and our study may be attributed to the fact that the previous clinical studies investigated effects of CGRP in healthy individuals only.

Although a novel study with several strengths such as a relatively homogeneous population at high risk of deranged glucose metabolism, a large sample size, robust statistical methodology, and comprehensive panel of pancreatic and gut hormones, there are several limitations that need to be acknowledged. First, only circulating plasma CGRP levels were measured. Tissue-specific CGRP levels would be a more accurate measure of physiological effect of CGRP, as plasma CGRP levels might be due to spillover (22). Pre-clinical studies showed that increased pancreatic storage of CGRP results in insulin resistance $(43,74)$. However, studies using radioimmunoassay, radio-receptor assay, and immunoradiometric assay demonstrated a strong correlation between the levels of CGRP in plasma and tissue extracts of rats and humans $(22,24)$. Also, CGRP levels were detectable in $>90 \%$ of the individuals involved in the present study, which reduces the chances that the detected levels in plasma were just due to spillover. Second, CHAP may be induced due to the genetic milieu of CGRP and insulin given that both are derived from chromosome 11 and are evolutionary homologues (14). Although, to the best of our knowledge, none of the patients in this study had genetical predisposition, we did not specifically screen for this. Third, we did not measure other calcitonin-family peptides, such as adrenomedullin and calcitonin, in our study population. Given that all procalcitonin derived peptides compete for CGRPr $(14,24)$, the potential effect of other peptides on glucose homeostasis in patients after acute pancreatitis may not be insignificant. Last, it is unknown whether decrease in circulating CGRP levels is due to reduced utility of CGRP or increased storage of CGRP in pancreatic tissue resulting in reduced spillover from perivascular nerves (14). A study conducted on Zucker rats showed that capsaicin-induced sensory nerve blockade benefits glucose tolerance (75). Pancreatic CGRP nerves are capsaicin-sensitive and, upon capsaicin-induced destruction, may have a beneficial effect on insulin secretion (76). The capsaicin-receptor antagonist, TRPV-1, also known to bind to CGRP $(76,77)$, should be investigated in future studies to better understand the mechanisms underlying the association between CGRP and glucose homeostasis.

\section{Conclusions}

CGRP is a ubiquitous peptide that may prove to be an early marker of diabetes of the exocrine pancreas, given its decrease in patients with CHAP and its association with glucagon and oxyntomodulin. This is further supported by the fact that glucagon and oxyntomodulin contribute considerably to circulating CGRP variance. Future studies investigating tissue-specific levels of CGRP, its role in gut barrier dysfunction, and the role of other calcitonin-derived peptides in glucose homeostasis are now warranted.

\section{Acknowledgements}

Funding: This study was part of the Clinical and epidemiOlogical inveStigations in Metabolism, nutritiOn, and pancreatic diseaseS (COSMOS) program. COSMOS is supported in part by the Health Research Council of New Zealand (grant 15/035 to Dr. Petrov), which played no role in the study design, collection, analysis, or interpretation of data, or writing of the manuscript.

\section{Footnote}

Conflicts of Interest: The authors have no conflicts of interest to declare.

Ethical Statement: The study protocol was approved by the Health Disability Ethics Committee (13/STH/182). Written informed consent was obtained from the patients for publication of this manuscript and any accompanying images.

\section{References}

1. American Diabetes Association. 2. Classification and Diagnosis of Diabetes. Diabetes Care 2016;39 Suppl 1:S13-22. 
2. Task Force Members, Rydén L, Grant PJ, et al. ESC Guidelines on diabetes, pre-diabetes, and cardiovascular diseases developed in collaboration with the EASD: the Task Force on diabetes, pre-diabetes, and cardiovascular diseases of the European Society of Cardiology (ESC) and developed in collaboration with the European Association for the Study of Diabetes (EASD). Eur Heart J 2013;34:3035-87.

3. Ewald N, Bretzel RG. Diabetes mellitus secondary to pancreatic diseases (Type 3c)--are we neglecting an important disease? Eur J Intern Med 2013;24:203-6.

4. Ewald N, Kaufmann C, Raspe A, et al. Prevalence of diabetes mellitus secondary to pancreatic diseases (type 3c). Diabetes Metab Res Rev 2012;28:338-42.

5. Shen HN, Yang CC, Chang YH, et al. Risk of Diabetes Mellitus after First-Attack Acute Pancreatitis: A National Population-Based Study. Am J Gastroenterol 2015;110:1698-706.

6. Pendharkar SA, Mathew J, Petrov MS. Age- and sexspecific prevalence of diabetes associated with diseases of the exocrine pancreas: A population-based study. Dig Liver Dis 2017;49:540-4.

7. Pendharkar SA, Mathew J, Zhao J, et al. Ethnic and geographic variations in the incidence of pancreatitis and post-pancreatitis diabetes mellitus in New Zealand: a nationwide population-based study. N Z Med J 2017;130:55-68.

8. Das SL, Kennedy JI, Murphy R, et al. Relationship between the exocrine and endocrine pancreas after acute pancreatitis. World J Gastroenterol 2014;20:17196-205.

9. Das SL, Singh PP, Phillips AR, et al. Newly diagnosed diabetes mellitus after acute pancreatitis: a systematic review and meta-analysis. Gut 2014;63:818-31.

10. Zelissen PM, Koppeschaar HP, Lips CJ, et al. Calcitonin gene-related peptide in human obesity. Peptides 1991;12:861-3.

11. Sgambato S, Carbone L, Giugliano D, et al. Effect of calcitonin on glucose--stimulated insulin secretion in normal, obese and prediabetic subjects. Farmaco Prat 1978;33:256-62.

12. Giugliano D, Passariello N, Sgambato S, et al. Calcitonin in diabetes. Lancet 1980;1:653.

13. Phillips AR, Abu-Zidan FM, Bonham MJ, et al. Amylin and severe acute pancreatitis. Pancreas 2000;20:105-6.

14. Russell FA, King R, Smillie SJ, et al. Calcitonin generelated peptide: physiology and pathophysiology. Physiol Rev 2014;94:1099-142.

15. Abbasi A, Corpeleijn E, Postmus D, et al. Plasma procalcitonin is associated with obesity, insulin resistance, and the metabolic syndrome. J Clin Endocrinol Metab 2010;95:E26-31.

16. Boursier G, Avignon A, Kuster N, et al. Procalcitonin, an Independent Marker of Abdominal Fat Accumulation in Obese Patients. Clin Lab 2016;62:435-41.

17. Singh RG, Pendharkar SA, Plank LD, et al. Role of human lipocalin proteins in abdominal obesity after acute pancreatitis. Peptides 2017;91:1-7.

18. Singh RG, Pendharkar SA, Gillies NA, et al. Associations between circulating levels of adipocytokines and abdominal adiposity in patients after acute pancreatitis. Clin Exp Med 2017;17:477-87.

19. Singh RG, Yoon HD, Wu LM, et al. Ectopic fat accumulation in the pancreas and its clinical relevance: A systematic review, meta-analysis, and meta-regression. Metabolism 2017;69:1-13.

20. Pendharkar SA, Asrani VM, Xiao AY, et al. Relationship between pancreatic hormones and glucose metabolism: A cross-sectional study in patients after acute pancreatitis. Am J Physiol Gastrointest Liver Physiol 2016;311:G50-8.

21. Gillies NA, Pendharkar SA, Singh RG, et al. Fasting levels of insulin and amylin after acute pancreatitis are associated with pro-inflammatory cytokines. Arch Physiol Biochem 2017;123:238-48.

22. Wimalawansa SJ. Amylin, calcitonin gene-related peptide, calcitonin, and adrenomedullin: a peptide superfamily. Crit Rev Neurobiol 1997;11:167-239.

23. van Rossum D, Hanisch UK, Quirion R. Neuroanatomical localization, pharmacological characterization and functions of CGRP, related peptides and their receptors. Neurosci Biobehav Rev 1997;21:649-78.

24. Wimalawansa SJ. Calcitonin gene-related peptide and its receptors: molecular genetics, physiology, pathophysiology, and therapeutic potentials. Endocr Rev 1996;17:533-85.

25. Aiyar N. Overview of Calcitonin Gene-Related Peptide and Its Receptor. Sci World J 2001;1:1.

26. Beglinger C, Koehler E, Born W, et al. Effect of calcitonin and calcitonin gene-related peptide on pancreatic functions in man. Gut 1988;29:243-8.

27. Bretherton-Watt D, Ghatei MA, Jamal H, et al. The physiology of calcitonin gene-related peptide in the islet compared with that of islet amyloid polypeptide (amylin). Ann N Y Acad Sci 1992;657:299-312.

28. Lewis CE, Clark A, Ashcroft SJ, et al. Calcitonin generelated peptide and somatostatin inhibit insulin release from individual rat B cells. Mol Cell Endocrinol 1988;57:41-9. 
29. Rasmussen TN, Bersani M, Schmidt P, et al. Isolation and molecular characterization of porcine calcitonin generelated peptide (CGRP) and its endocrine effects in the porcine pancreas. Pancreas 1998;16:195-204.

30. Hermansen K, Ahrén B. Dual effects of calcitonin generelated peptide on insulin secretion in the perfused dog pancreas. Regul Pept 1990;27:149-57.

31. Morishita T, Yamaguchi A, Yamatani T, et al. Effects of islet amyloid polypeptide (amylin) and calcitonin generelated peptide (CGRP) on glucose metabolism in the rat. Diabetes Res Clin Pract 1992;15:63-9.

32. Seifert H, Sawchenko P, Chesnut J, et al. Receptor for calcitonin gene-related peptide: binding to exocrine pancreas mediates biological actions. Am J Physiol 1985;249:G147-51.

33. Leighton B, Cooper GJ. Pancreatic amylin and calcitonin gene-related peptide cause resistance to insulin in skeletal muscle in vitro. Nature 1988;335:632-5.

34. Pendharkar SA, Asrani VM, Murphy R, et al. The Role of Gut-brain Axis in Regulating Glucose Metabolism After Acute Pancreatitis. Clin Transl Gastroenterol 2017;8:e210.

35. Adeghate E. Distribution of calcitonin-gene-related peptide, neuropeptide-Y, vasoactive intestinal polypeptide, cholecystokinin-8, substance $\mathrm{P}$ and islet peptides in the pancreas of normal and diabetic rats. Neuropeptides 1999;33:227-35.

36. Kraenzlin ME, Ch'ng JL, Mulderry PK, et al. Infusion of a novel peptide, calcitonin gene-related peptide (CGRP) in man. Pharmacokinetics and effects on gastric acid secretion and on gastrointestinal hormones. Regul Pept 1985;10:189-97.

37. Nilsson C, Hansen TK, Rosenquist C, et al. Long acting analogue of the calcitonin gene-related peptide induces positive metabolic effects and secretion of the glucagonlike peptide-1. Eur J Pharmacol 2016;773:24-31.

38. Pettersson M, Ahrén B. Insulin and glucagon secretion in rats: effects of calcitonin gene-related peptide. Regul Pept 1988;23:37-50.

39. Yamatani T, Kadowaki S, Chiba T, et al. Calcitonin gene-related peptide stimulates somatostatin release from isolated perfused rat stomach. Endocrinology 1986;118:2144-5.

40. Dellinger EP, Forsmark CE, Layer P, et al. DeterminantBased Classification of Acute Pancreatitis Severity: An International Multidisciplinary Consultation. Ann Surg 2012;256:875-80.

41. Gelman A, Hill J, Yajima M. Why We (Usually) Don't Have to Worry About Multiple Comparisons. J Res Educ
Eff 2012;5:189-211.

42. Molina JM, Cooper GJ, Leighton B, et al. Induction of insulin resistance in vivo by amylin and calcitonin generelated peptide. Diabetes 1990;39:260-5.

43. Young AA, Crocker LB, Wolfe-Lopez D, et al. Daily amylin replacement reverses hepatic glycogen depletion in insulin-treated streptozotocin diabetic rats. FEBS Lett 1991;287:203-5.

44. Edwards BJ, Perry HM, Kaiser FE, et al. Age-related changes in amylin secretion. Mech Ageing Dev 1996;86:39-51.

45. Wang MW, Young AA, Rink TJ, et al. 8-37h-CGRP antagonizes actions of amylin on carbohydrate metabolism in vitro and in vivo. FEBS Lett 1991;291:195-8.

46. Zhu GC, Dudley DT, Saltiel AR. Amylin increases cyclic AMP formation in L6 myocytes through calcitonin generelated peptide receptors. Biochem Biophys Res Commun 1991;177:771-6.

47. Kubota M, Moseley JM, Butera L, et al. Calcitonin gene-related peptide stimulates cyclic AMP formation in rat aortic smooth muscle cells. Biochem Biophys Res Commun 1985;132:88-94.

48. Tschopp FA, Henke H, Petermann JB, et al. Calcitonin gene-related peptide and its binding sites in the human central nervous system and pituitary. Proc Natl Acad Sci U S A 1985;82:248-52.

49. Gon G, Giaid A, Steel JH, et al. Localization of immunoreactivity for calcitonin gene-related peptide in the rat anterior pituitary during ontogeny and gonadal steroid manipulations and detection of its messenger ribonucleic acid. Endocrinology 1990;127:2618-29.

50. Ju G, Liu SJ, Ma D. Calcitonin gene-related peptideand substance P-like-immunoreactive innervation of the anterior pituitary in the rat. Neuroscience 1993;54:981-9.

51. Panaro BL, Tough IR, Engelstoft MS, et al. The melanocortin-4 receptor is expressed in enteroendocrine $\mathrm{L}$ cells and regulates the release of peptide YY and glucagonlike peptide 1 in vivo. Cell Metab 2014;20:1018-29.

52. Giugliano D. Calcitonin and the human endocrine pancreas. Biomed Pharmacother 1984;38:273-7.

53. Giugliano D, Passariello N, Sgambato S, et al. Calcitonin modulation of insulin and glucagon secretion in man. Am J Physiol 1982;242:E206-13.

54. Passariello N, Giugliano D, Sgambato S, et al. Calcitonin, a diabetogenic hormone? J Clin Endocrinol Metab 1981;53:318-23.

55. Cani PD, Plovier H, Van Hul M, et al. Endocannabinoids-at the crossroads between the gut microbiota and host 
metabolism. Nat Rev Endocrinol 2016;12:133-43.

56. Ammori BJ, Becker KL, Kite P, et al. Calcitonin precursors: early markers of gut barrier dysfunction in patients with acute pancreatitis. Pancreas 2003;27:239-43.

57. Pendharkar SA, Singh RG, Petrov MS. Cross-talk between innate cytokines and the pancreatic polypeptide family in acute pancreatitis. Cytokine 2017;90:161-8.

58. Gillies N, Pendharkar SA, Asrani VM, et al. Interleukin-6 is associated with chronic hyperglycemia and insulin resistance in patients after acute pancreatitis. Pancreatology 2016;16:748-55.

59. Wu LM, Sankaran SJ, Plank LD, et al. Meta-analysis of gut barrier dysfunction in patients with acute pancreatitis. Br J Surg 2014;101:1644-56.

60. Everard A, Cani PD. Diabetes, obesity and gut microbiota. Best Pract Res Clin Gastroenterol 2013;27:73-83.

61. Pachikian BD, Essaghir A, Demoulin JB, et al. Prebiotic approach alleviates hepatic steatosis: implication of fatty acid oxidative and cholesterol synthesis pathways. Mol Nutr Food Res 2013;57:347-59.

62. Neyrinck AM, Van Hée VF, Piront N, et al. Wheatderived arabinoxylan oligosaccharides with prebiotic effect increase satietogenic gut peptides and reduce metabolic endotoxemia in diet-induced obese mice. Nutr Diabetes 2012;2:e28.

63. Upadhyaya S, Banerjee G. Type 2 diabetes and gut microbiome: at the intersection of known and unknown. Gut Microbes 2015;6:85-92.

64. Patterson E, Ryan PM, Cryan JF, et al. Gut microbiota, obesity and diabetes. Postgrad Med J 2016;92:286-300.

65. Delzenne NM, Cani PD, Everard A, et al. Gut microorganisms as promising targets for the management of type 2 diabetes. Diabetologia 2015;58:2206-17.

66. Geurts L, Neyrinck AM, Delzenne NM, et al. Gut microbiota controls adipose tissue expansion, gut barrier and glucose metabolism: novel insights into molecular targets and interventions using prebiotics. Benef Microbes 2014;5:3-17.

67. Cooper GJ, Willis AC, Clark A, et al. Purification and characterization of a peptide from amyloid-rich pancreases of type 2 diabetic patients. Proc Natl Acad Sci U S A 1987;84:8628-32.

68. Nishi M, Sanke T, Nagamatsu S, et al. Islet amyloid polypeptide. A new beta cell secretory product related to islet amyloid deposits. J Biol Chem 1990;265:4173-6.

69. Ishizuka J, Greeley GH, Cooper CW, et al. Effect of calcitonin gene-related peptide on glucose and gastric inhibitory polypeptide-stimulated insulin release from cultured newborn and adult rat islet cells. Regul Pept 1988;20:73-82.

70. Ohsawa H, Kanatsuka A, Yamaguchi T, et al. Islet amyloid polypeptide inhibits glucose-stimulated insulin secretion from isolated rat pancreatic islets. Biochem Biophys Res Commun 1989;160:961-7.

71. Fujimura M, Greeley GH, Hancock MB, et al. Colocalization of calcitonin gene-related peptide and somatostatin in pancreatic islet cells and inhibition of insulin secretion by calcitonin gene-related peptide in the rat. Pancreas 1988;3:49-52.

72. Tedstone AE, Nezzer T, Hughes SJ, et al. The effect of islet amyloid polypeptide (amylin) and calcitonin generelated peptide on glucose removal in the anaesthetized rat and on insulin secretion from rat pancreatic islets in vitro. Biosci Rep 1990;10:339-45.

73. Kogire M, Ishizuka J, Thompson JC, et al. Inhibitory action of islet amyloid polypeptide and calcitonin generelated peptide on release of insulin from the isolated perfused rat pancreas. Pancreas 1991;6:459-63.

74. Kreutter DK, Orena SJ, Torchia AJ, et al. Amylin and CGRP induce insulin resistance via a receptor distinct from cAMP-coupled CGRP receptor. Am J Physiol 1993;264:E606-13.

75. Gram DX, Hansen AJ, Wilken M, et al. Plasma calcitonin gene-related peptide is increased prior to obesity, and sensory nerve desensitization by capsaicin improves oral glucose tolerance in obese Zucker rats. Eur J Endocrinol 2005;153:963-9.

76. Gram DX, Ahrén B, Nagy I, et al. Capsaicin-sensitive sensory fibers in the islets of Langerhans contribute to defective insulin secretion in Zucker diabetic rat, an animal model for some aspects of human type 2 diabetes. Eur J Neurosci 2007;25:213-23.

77. Evangelista S. Capsaicin receptor as target of calcitonin gene-related peptide in the gut. Prog Drug Res 2014;68:259-76.

Cite this article as: Pendharkar SA, Walia M, Drury M, Petrov MS. Calcitonin gene-related peptide: neuroendocrine communication between the pancreas, gut, and brain in regulation of blood glucose. Ann Transl Med 2017;5(21):419 doi: 10.21037/atm.2017.08.27 